\title{
ALTAS HABILIDADES OU SUPERDOTAÇÃO E PERDA AUDI- TIVA: DUPLICIDADE DE NECESSIDADES EDUCACIONAIS ESPECIAIS E POLÍTICAS PÚBLICAS*
}

\section{HIGH ABILITIES OR GIFTEDNESS AND HEARING LOSS: TWICE SPECIAL EDUCA- TIONAL NEEDS AND PUBLIC POLICIES \\ ALTAS HABILIDADES O SOBREDOTACIÓN Y PÉRDIDA AUDITIVA: DOBLE NECESI- DAD EDUCACIONAL ESPECIAL Y POLÍTICA PÚBLICA}

\author{
Rosemeire de Araújo Rangni \\ Doutora em Educação Especial Universidade Federal de São Carlos \\ Maria da Piedade Resende da Costa \\ Doutora em Psicologia Experimental pela Universidade de São Paulo
}

\begin{abstract}
RESUMO: Com caráter inclusivo, as leis educacionais brasileiras e as ações políticas direcionam os serviços da Educação Especial ao categorizar as necessidades educacionais especiais (NEE) e separá-las em grupos, quais sejam: deficiências, transtorno global do desenvolvimento e altas habilidades ou superdotação. Este artigo objetiva expor (i) a possibilidade de educandos possuirem duplicidade de NEE, no caso em questão, altas habilidades ou superdotação e perda auditiva e (ii) as implicações dos serviços educacionais vigentes com as políticas públicas. O presente artigo se deu por meio de pesquisas bibliográficas e documentais. Os resultados indicaram que o sistema educacional brasileiro, voltado à Educação, privilegia a identificação e o atendimento dos educandos com NEE de maneira categorial, não contemplando a possibilidade de figurarem concomitantemente em duas categorias de NEE - altas habilidades ou superdotação e perda auditiva -, foco deste estudo.
\end{abstract}

PALAVRAS-CHAVE: Duplicidade de necessidades educacionais especiais. Perda auditiva. Altas habilidades ou superdotação.

ABSTRACT: With the inclusive perspective, the Brazilian educational laws and the politic actions guide the Special Educational services when categorize the special educational needs (SEN) getting them apart in groups as well: disabilities, developmental disturbs, and high skills or giftedness. This paper aims to show (i) the possibility of the student with twice SEN, in case the high skills or giftedness and hearing loss and (ii) the implications of the educational services and public policies. The present paper was done by bibliographical and documental researches. The results indicate that the Brazilian educational system for the special education privileges the identification and the provisions for the SEN students on the categorical way. It doesn't consider the students possibilities to be in two categories of the SEN - high skills or giftedness and hearing loss, aim of this study.

KEYWORDS: Twice special educational needs. Hearing loss. High skills or giftedness.

RESUMEN: Con una perspectiva inclusiva, las leyes educacionales brasileñas y las acciones políticas dirigen los servicios de la educación especial al clasificar las necesidades educacionales especiales (NEE) dividiéndolas en grupos cuales sean: discapacidades, trastornos globales del desarrollo y altas habilidades o sobredotación. Este artículo se propone presentar (i) la posibilidad de tener esos estudiantes doble NEE, en caso de altas habilidades o sobredotación y pérdida auditiva y (ii) las implicaciones de los servicios vigentes y las políticas públicas. El presente artículo se desarrolló por medio de investigación bibliográfica y documental. Los resultados indicaron que el sistema educacional brasileño para la educación especial privilegia la identificación y atención a los estudiantes con NEE de manera categorial, no contemplando la posibilidad de los estudiantes representarse al mismo tiempo en dos categorías de NEE - altas habilidades o sobredotación y pérdida auditiva.

PALABRAS CLAVE: Doble necesidad educacional especial. Pérdida auditiva. Altas habilidades o sobredotación.

\footnotetext{
* Trabalho premiado durante o XXV Encontro do SEMIC, realizado na UFMA, entre os dias 18 a 22 de novembro de 2013. Artigo recebido em fevereiro de 2014

Aprovado abril de 2014
} 


\section{1 | Introdução}

Sobre as necessidades educacionais especiais (NEE), é perceptível a relevância de discussões nos âmbitos conceitual, de atendimento e de ações políticas. Esse fato nos orienta a uma visão dicotômica ou facetada das categorias dessas necessidades, ou seja, o foco dado às NEE varia de acordo com a cultura organizacional dos sistemas educacionais.

Um dos dispositivos legais mais recentes, denominado Política Nacional de Educação Especial na Perspectiva da Educação Inclusiva (BRASIL, 2008), classifica para fins de atendimento educacional especializado as seguintes categorias de NEE: deficiência, transtornos globais de desenvolvimento e altas habilidades ou superdotação ${ }^{1}$, entendidas como público assistido pela Educação Especial.

Nesses três grupos, o atendimento é realizado por categorias e não há dados, no Censo Escolar, indicando que esses educandos, em situação de inclusão, possam ser identificados e atendidos em duas categorias, exceção feita à deficiência múltipla.

A categorização apontada e, para efeito de atendimento especializado (BRASIL, 2011), alude que o sistema classifica os estudantes, na maioria dos casos, "laudados" clinicamente em detrimento de uma avaliação educacional. Neste ponto de vista, Omote $(1994,1996)$ assinala que a especificidade de deficiências ou sua categorização orienta os serviços para essa população, bem como investe na formação de profissionais para atuar com tipos específicos de deficiência, relegando a contemplação da deficiência de um modo geral. Dessa forma, o referido autor argumenta a categorização como forma de contribuição às diferenças.

Surgem, então, alguns questionamentos:

a) O que impossibilita o sistema identificar e atender estudantes que apresentem, ao mesmo tempo, altas habilidades ou superdotação combinado a alguma deficiência, especificamente a perda auditiva?

b) Por que o sistema educacional rejeita considerar a condição de duplicidade de NEE?

Por meio de uma breve observação dos estudos sobre a duplicidade de NEE - altas habilidades ou superdotação e outra NEE -, é possível constatar que o reconhecimento dessa condição é necessário. Faz-se, cada vez mais urgente, a conscientização dessa possibilidade para que se possa evitar que os educandos sejam atendidos em uma só categoria de NEE, consumando, assim, a unicidade categorizante e, comumente, voltada para as limitações em detrimento das potencialidades.

Sob esse viés, os apontamentos apresentados refletem o foco na inclusão e/ou exclusão de necessidades educacionais especiais recomendadas na legislação brasileira pertinente à Educação e Educação Especial mais recente, quais sejam: Decreto n 7.611 (BRASIL, 2011) e Lei $n^{\circ} 12.796$ (BRASIL, 2013), entre outras, que definem quais as categorias de NEE a serem atendidas pelos serviços especializados. Este artigo expõe a duplicidade de NEE - altas habilidades ou superdotação e perda auditiva - para que essa possibilidade dual possa ser explorada.

Frente a isso, este artigo tem como objetivos:

a) expor a possibilidade dos educandos possuírem duplicidade de NEE, no caso em questão, altas habilidades ou superdotação e perda auditiva, e as implicações legais envolvidas pelas políticas públicas;

\footnotetext{
${ }^{1}$ Altas habilidades ou superdotação é termo utilizado na Lei de Diretrizes e Bases da Educação Nacional n 9.394 , de 1996, e, atualizada pela Lei $n^{\circ} 12.796$, de 2013. Apesar da divergência conceitual e terminológica entre os estudiosos da área e dos documentos legais, este artigo usará os termos altas habilidades ou superdotação e perda auditiva, porém, respeitará as citações dos autores e documentos.
} 
b) apresentar brevemente as políticas públicas referentes à temática;

c) expor algumas publicações encontradas sobre a duplicidade explorada: altas habilidades ou superdotação e perda auditiva.

\section{2 | Método}

Para a execução do estudo, utilizou-se pesquisas bibliográfica e documental. Para tanto, recorreu-se às pesquisas em documentos oficiais pertinentes à Educação e Educação Especial, como também, livros, artigos científicos disponíveis em sites como Council for Exceptional Children (CEC), National Association for Gifted Children (NAGC) e Educational Resources Information Center (ERIC), no ano de 2012, e na Biblioteca Eletrônica Científica Online (SciELO Brasil), no ano de 2013. Como filtros de pesquisa, os termos: "giftedness", "gifted", "high abilities" conjugada com "hearing loss", "hearing disabilitiy", "deafness", "altas habilidades/superdotação", "altas habilidades", "superdotação", "surdez", "deficiência”, "dupla excepcionalidade”, "duplicidade de necessidades educacionais especiais" foram utilizados enquanto palavras-chave para a busca pretendida. Os trabalhos encontrados foram analisados por meio dos seus resumos e os textos completos disponibilizados nos corpora pesquisados.

\section{3 | Políticas públicas: reflexões iniciais}

Para iniciar a discussão, é pertinente que se apresente quem são os educandos com NEE atendidos pela Educação Especial no Brasil e como eles estão legalmente citados na Constituição.

Em 1996, foi promulgada a Lei de Diretrizes e Bases da Educação Nacional (LDBEN) $n^{\circ} 9.394$ (BRASIL, 1996) que, pela primeira vez, trouxe, em seu texto, artigos dedicados à Educação Especial, são eles os artigos $59^{\circ}$ ao $60^{\circ}$, Capítulo V. A referida Lei veio reforçar e incentivar políticas voltadas para as necessidades educacionais especiais, no entanto, essa Lei não explicita quem seriam os educandos atendidos, apenas mencionando-os como "educandos portadores de necessidades especiais" (artigo 58) e "superdotados" (artigo 59, II), ambas denominações adotadas em 1996, ano de sua promulgação. Aliás, a única categoria de NEE mencionada nesse dispositivo foi a dos "superdotados", no entanto, uma alteração ocorreu na mencionada Lei, em 2013, substituindo o termo "necessidades especiais" por "educando com deficiência, transtornos globais do desenvolvimento e altas habilidades ou superdotação".

Desde 1994, a Política Nacional de Educação Especial, publicada pelo Ministério da Educação e do Desporto (MEC) e Secretaria de Educação Especial (SEESP) (BRASIL, 1994a), configurava em suas diretrizes quem seria o alunado da Educação Especial, ao elencar as categorias: altas habilidades, condutas típicas, deficiência auditiva, deficiência física, deficiência mental, deficiência múltipla e deficiência visual.

A Política Nacional de Educação Especial (BRASIL, 1994a, p. 45) tinha como objetivo geral:

servir como fundamentação e orientação do processo global da educação de pessoas portadoras de deficiências, de condutas típicas e de altas habilidades, criando condições adequadas para o desenvolvimento pleno de suas potencialidades, com vistas ao exercício consciente da cidadania.

E acrescentava que "a divulgação deste documento facilitaria o trabalho dos profissionais da educação que atuam na área, garantindo o atendimento especializado a todos os alunos que fazem jus à educação especial no Brasil" (BRASIL, 1994a, p. 10, grifo nosso). 
Percebe-se que qualquer outra categoria de NEE que, por ventura, surgisse entre os educandos, estaria excluída do atendimento da Educação Especial, haja vista que as recomendações da Declaração de Salamanca (BRASIL, 1994b) ampliavam o leque de NEE e possuía princípios inclusivos².

A Política Nacional de Educação Especial (BRASIL, 1994a) deu lugar à Política Nacional de Educação Especial na Perspectiva da Educação Inclusiva (BRASIL, 2008, p. 9) com nova orientação e abordagem inclusiva, porém, gessando as necessidades especiais a serem atendidas em três grupos: 1. Pessoa com deficiência - "aquela que tem impedimento de longo prazo, de natureza física, mental ou sensorial que, em interação com diversas barreiras, pode ter restringida sua participação plena e efetiva na escola e na sociedade"; 2 . Transtornos globais do desenvolvimento - "são aqueles que apresentam alterações qualitativas das interações sociais recíprocas e na comunicação, um repertório de interesses e atividades restritos, estereotipados e repetitivos"; e 3. Altas habilidades/superdotação definido como o conjunto daqueles:

que demonstram potencial elevado em qualquer uma das seguintes áreas, isoladas ou combinadas: intelectual, acadêmica, de liderança, psicomotricidade e artes, além de apresentar grande criatividade, envolvimento na aprendizagem e realização de tarefas em áreas de seu interesse (BRASIL, 2008, p. 9).

No aporte legal que orienta as ações políticas e pedagógicas, ficam excluídas do mencionado documento outras NEE Nessa perspectiva, entretanto, é comum serem contemplados na literatura da área como NEE outros transtornos funcionais, como em Montgomery (2003) e Ourofino (2007), dentre outros autores.

O Decreto $n^{\circ} 7.611$ que dispõe sobre o atendimento educacional especializado mantém na Política Nacional os três grupos a serem atendidos, pontuando que os estudantes com altas habilidades ou superdotação devem receber atendimento suplementar às suas áreas de potencial (BRASIL, 2011). Em igual valor, está o atendimento complementar aos que se encontram em situação de deficiência ou transtorno global do desenvolvimento. Infere-se, com a leitura do mencionado documento, que estão garantidos os direitos de atendimento e a dupla matrícula aos alunos com NEE, porém, não há menção de garantias aos estudantes que são diagnosticados com altas habilidades ou superdotação e outra NEE conjugada.

\section{4 | Altas habilidades ou superdotação e perda auditiva}

A temática das altas habilidades ou superdotação converte-se em uma abordagem teórica, densa e de muitas polêmicas. Ela é vista com desatenção em relação às outras NEE e isso se dá, possivelmente, porque os educandos que se destacam por seu potencial elevado estão rodeados de mitos, preconceitos e exclusão. Prova disso é o número ínfimo de educandos identificados e atendidos no Brasil. Segundo o Censo Escolar 2010, o número de matrículas realizadas era de 5.186 (FREITAS; PÉREZ, 2010), em um universo de mais de 50 milhões de escolares no país e, em 2012, esse número não ultrapassou 13.000 matrículas (DELOU, 2012).

Muitos educadores, professores, gestores e coordenadores desconhecem o tema e são justamente esses profissionais que consideram os seus estudantes com altas habilidades ou superdotação apenas como parte de uma educação de elite ou, ainda, que esses educandos talen-

\footnotetext{
${ }^{2} \mathrm{O}$ princípio que orienta esta Estrutura é o de que escolas deveriam acomodar todas as crianças independentemente de suas condições físicas, intelectuais, sociais, emocionais, linguísticas ou outras. Aquelas deveriam incluir crianças deficientes e super-dotadas, crianças de rua e que trabalham, crianças de origem remota ou de população nômade, crianças pertencentes a minorias linguísticas, étnicas ou culturais, e crianças de outros grupos desvantajados ou marginalizados. Tais condições geram uma variedade de diferentes desafios aos sistemas escolares (BRASIL, 1994b).
} 
tosos podem caminhar por si mesmos nas trilhas educacionais. Mitos e imaginários de crenças acarretam barreiras para que o reconhecimento dos alunos que se destacam chegue às escolas onde já estão muitas vezes integrados, porém, sem serem percebidos (ALENCAR; FLEITH, 2001; FREITAS; PÉREZ, 2010). São fatores como esses que contribuem para que haja exclusão e, em muitos casos, a evasão dessa população de estudantes da escola.

Em contrapartida, os educandos com deficiências têm recebido mais apoio do sistema escolar, especialmente após os pressupostos da Declaração de Salamanca (BRASIL, 1994), adentrando, em maior número, em escolas comuns. É o caso dos educandos com perda auditiva.

Segundo Sales et al. (2010), o indivíduo com incapacidade auditiva é aquele cuja percepção de sons não é funcional na vida comum, ou aquele cuja percepção de sons, ainda que comprometida, possui algum grau de funcionalidade com ou sem prótese auditiva. Esses indivíduos são chamados de pessoas com deficiência auditiva.

Nos limites deste texto, apesar da importância, não se pretende discutir com profundidade os conceitos e terminologias da surdez e da deficiência auditiva. Seria necessário abordá-las, no mínimo, nas vertentes clínica, linguística e educacional de seu uso, Também, a discussão se tornaria extensa ao apresentar as divergências terminológicas em documentos pertinentes tais como: a Lei no 10.436 (BRASIL, 2002) que dispõe sobre a Língua Brasileira de Sinais e o Decreto $n^{\circ} 5.626$ (BRASIL, 2005) que regulamenta a Lei no 10.436, de 24 de abril de 2002, dispondo sobre a Língua Brasileira de Sinais (Libras). Esses dispositivos legais expõem o conflito do uso terminológico entre surdez e deficiência auditiva, aquela que defende o uso da Língua Brasileira de Sinais (Libras) e esta, por ser composta de indivíduos oralizados na língua da comunidade ouvinte que não utilizam Libras, ou mesmo que façam uso de aparelhos auditivos.

Outra discussão interessante aponta para a utilização da nomenclatura "Libras". De acordo com Sassaki (2005), a forma correta de escrita é com o "L" maiúsculo e as outras letras em minúsculo, significando "Li" de Língua de Sinais, e "bras" de Brasileira. No entanto, os dispositivos legais trazem a nomenclatura em maiúscula "LIBRAS", mas, cada letra não significa uma palavra.

Importa para a discussão que a perda auditiva existe em ambos os grupos, surdos e com deficiência auditiva e que necessitam de atendimento educacional especializado.

O Censo Escolar mostrou que em 2006, o total de matrículas em todas as necessidades especiais foi de 700.624 e que destes, 69.420 educandos possuíam perda auditiva, leve ou severa. Neste contexto, a Organização Mundial da Saúde (OMS) aponta que, apenas em duas áreas (verbal e lógico-matemática), 3,5 a 5\% de qualquer população são superdotados (SABATELLA, 2005), dessa forma, é possível inferir que, em qualquer população, pode haver indivíduos com potencial acima da média, inclusive aqueles que apresentem, concomitantemente, alguma outra NEE.

Ao proceder a identificação em educandos com perda auditiva, das séries iniciais e com características de altas habilidades ou superdotação, Negrini (2009) chegou ao índice de $25 \%$ e, para estes, não foram reveladas limitações em outras áreas do domínio humano.

Smith (2008, p. 211) assinala que pessoas com deficiência que desenvolveram habilidades proeminentes como Ludwig Van Beethoven, Helen Keller, entre outros, independente de suas deficiências graves, trouxeram contribuições com seus talentos e ressalta: "lembre-se de que, não importa qual seja a deficiência, alguém pode ter capacidades, habilidades ou criatividade excepcionais".

A educação de alunos com perda auditiva é debatida, entretanto não se configura de fácil operacionalidade. Há posições contrárias à sua inclusão em classes comuns, principalmente nos casos de perda severa e profunda que, muitas vezes, não têm essa diversidade linguística atendida satisfatoriamente, como também, acaba por direcionar as propostas pedagógicas para a incapacidade. Por falta de recursos humanos nos ambientes escolares, no que diz respeito ao intérprete de Libras e/ ou aparelhos auditivos adequados, os estudantes ficam limitados ao acesso aos conteúdos curriculares. 
Negrini (2009) assinala que a comunidade de indivíduos com surdez (a comunidade surda não se considera deficiente) prefere, muitas vezes, instituições onde possam utilizar (a Libras e outras práticas sociais próprias de sua cultura, consideradas espaços de resistência e luta contra práticas ouvintes.

Winstanley (2003) assinala que é difícil definir a duplicidade de NEE. Salienta que a variedade de termos para definir altas habilidades ou superdotação, bem como, a complexidade da Cultura Surda dificulta o reconhecimento da duplicidade em indivíduos surdos, o que faz disso unicidade entre as deficiências. Diz, também, que encontrar material sobre os que possuem potencial elevado, além da perda auditiva, provou ser tarefa complexa.

Guenther (2000, p. 27) explicita que talentosa é a pessoa que realiza com alto grau de qualidade, alcançando reconhecido sucesso, algo que representa expressão de uma característica que a sociedade reconhece e aprecia, ou desempenha em nível de qualidade superior alguma área que a sociedade valoriza. É questionado, porém, segundo a mencionada autora, se as pessoas com deficiências podem ser parte de um grupo valorizado pela sociedade, uma vez reconhecidas social e culturalmente.

Ainda Guenther (2011), embasada em Gagné $(2005,2008)$, salienta que a dotação ${ }^{3}$ é um construto que designa posse e uso de notável capacidade natural, um dom dado ao indivíduo pela vida e, assim, relacionado à origem genética, estando o talento mais enraizado na aquisição do que na herança. Sobre esse conceito, reflete-se que os próprios indivíduos com perda auditiva e suas dificuldades comunicacionais podem interferir no desenvolvimento de sua capacidade natural.

Na perspectiva de Gagné (2010, p. 3), o desenvolvimento do talento "é formalmente definido como engajamento sistemático por parte dos talentees ${ }^{4}$ por um período de tempo significativo, em um programa estruturado de atividades levando a uma meta específica de excelência”. Possivelmente, sem a identificação dos potenciais dos educandos com perda auditiva é quase impossível engajá-los aos programas implementados para altas habilidades ou superdotação, pois, o olhar do educador está na limitação e não nas potencialidades (WINSTANLEY, 2003).

As características para alunos com duplicidade de NEE, altas habilidades ou superdotação e perda auditiva, indicados pelo Education Resource Information Center (2007) são:

Leitura precoce;

a) excelente memória;

b) habilidade em ajustar-se à escola regular;

c) habilidades na fala e leitura sem instrução;

d) rapidez no domínio das ideias;

e) habilidade de raciocinar;

f) alta performance na escola;

g) muitos interesses;

h) maneira não tradicional de absorver problemas;

i) habilidades de resolver problemas do dia a dia, possivelmente em alto nível;

j) atraso em conhecimento de conceitos;

k) alta iniciativa;

I) senso de humor;

m) intuição;

n) engenhosidade em resolver problemas;

o) habilidade em linguagem de símbolos.

${ }^{3}$ Dotação e talento são termos utilizados pelo pesquisador canadense Francoys Gagné.

${ }^{4}$ Talentees - neologismo criado por Gagné (2010) para descrever qualquer pessoa participante de um programa sistemático de desenvolvimento de talento. 
Se existem todos esses critérios para indivíduos com a mencionada duplicidade, então, onde estariam as dificuldades em se enquadrar o indivíduo Surdo no patamar de altas habilidades ou superdotação? Há escassez de serviços aos estudantes com potencial elevado e ínfimos programas que os atendem, mesmo para alunos sem qualquer deficiência, conforme índices de matrículas apresentadas anteriormente, assim como, a falta de formação dos professores e educadores em geral sobre a temática que leve a possibilidade de reconhecimento das altas habilidades ou superdotação em alunos com deficiência (RANGNI, 2012). Nessa ótica, é possível inferir que há dicotomia de reconhecimento/atendimento dos estudantes com NEE por categorias e exclusão nos serviços educacionais especializados.

Negrini (2009), em sua pesquisa realizada para identificar características de altas habilidades ou superdotação em 28 crianças surdas, pré-escolares e dos ciclos iniciais em escola especializada, salienta que as características encontradas, pessoais e individuais, são consonantes às outras crianças. Menciona, todavia, que as características poderiam ser observadas em outras instituições de ensino, uma vez que a escola especializada já facilita a identificação de seus estudantes porque nela é valorizada a Libras e a sua forma de comportamento, interesses e habilidades.

As características de educandos com duplicidade de NEE - altas habilidades ou superdotação e perda auditiva - têm semelhanças com as características apresentadas pelo Ministério da Educação para alunos com altas habilidades ou superdotação (BRASIL, 2002), quais sejam:

a) grande curiosidade, envolvimento com muitos tipos de atividades exploratórias;

b) autoiniciativa;

c) originalidade de expressão oral e escrita;

d) talento incomum para expressão em artes;

e) habilidade para apresentar alternativas de soluções com flexibilidade de pensamentos;

f) abertura para a realidade, sagacidade e capacidade de observação;

g) capacidade de enriquecimento com situação-problema;

h) capacidade para usar conhecimento e informação;

i) combinação de elementos, ideias e experiência de forma peculiar;

j) capacidade de julgamento e avaliação superiores;

k) produção de ideias e respostas variadas;

l) gosto por correr riscos;

$\mathrm{m})$ habilidade em ver relações entre fatos;

n) aprendizado rápido, fácil e eficiente, especialmente em sua área de interesse.

Entretanto, é importante ressaltar que uma pessoa com indicadores potencialmente superiores não apresenta todas as características relacionadas, simultaneamente.

As áreas consideradas para as altas habilidades ou superdotação são a intelectual, a acadêmica, da psicomotricidade, de artes, liderança e criatividade (BRASIL, 2008) e os educandos podem apresentá-las isoladas ou combinadamente. Canalizar atenção ou priorizar intervenções pedagógicas às dificuldades é negar o direito de desenvolverem suas potencialidades fora de suas limitações.

Ainda permanece nas escolas brasileiras, onde os educandos com altas habilidades ou superdotação não são reconhecidos, uma perda imensurável, contribuindo para que esses estudantes acabem se evadindo após iminente fracasso escolar por conta de categorizações padronizantes de atendimento (OMOTE, 1994, 1996). Possivelmente, quando esses estudantes encontram respaldo, este se dá fora dos muros escolares. Então, onde está o papel da escola e as ações políticas em atender a todos em suas singularidades e especificidades? De qual inclusão estamos falando? 


\section{5 | Resultados e discussão}

Após busca realizada em livros sobre a temática e artigos acadêmicos disponíveis na Rede Mundial de Computadores (Internet), especificamente em sites como Council for Exceptional Children (CEC), National Association for Gifted Children (NAGC) e Educational Resources Information Center (ERIC), no ano de 2012, e na Biblioteca Eletrônica Científica Online (SciELO Brasil), no ano de 2013, foram obtidos os seguintes resultados conforme indicação contida no quadro 1.

Quadro 1 - Duplicidade de Necessidades Educacionais Especiais: altas habilidades ou superdotação e perdas auditivas

\begin{tabular}{|c|l|l|l|l|}
\hline Ordem & $\begin{array}{l}\text { Tipo de } \\
\text { Publicação }\end{array}$ & Ano & Autor(es) & Título \\
\hline 1 & Editorial & s/d & $\begin{array}{l}\text { Council for Exceptional } \\
\text { Children -CEC }\end{array}$ & Twice exceptional. \\
\hline 2 & Artigo & s/d & $\begin{array}{l}\text { Council for Exceptional } \\
\text { Children - CEC }\end{array}$ & $\begin{array}{l}\text { Children with communication } \\
\text { disorders. }\end{array}$ \\
\hline 3 & Artigo & s/d & Carolyn Cosmos & $\begin{array}{l}\text { Imagine teaching Robin } \\
\text { Williams. Twice exceptional } \\
\text { children in your school. }\end{array}$ \\
\hline 4 & Artigo & s/d & $\begin{array}{l}\text { National Association for } \\
\text { Gifted Children - NAGC }\end{array}$ & $\begin{array}{l}\text { Twice exceptional (gifted with } \\
\text { special needs). }\end{array}$ \\
\hline 5 & Artigo & 1996 & Vialle, W.; Paterson, J. & $\begin{array}{l}\text { Constructing a culturally } \\
\text { sensitive education for gifted } \\
\text { deafstudents. }\end{array}$ \\
\hline 6 & Artigo & 1989 & $\begin{array}{l}\text { Yewchuk,C.; Bibby, } \\
\text { M. A. }\end{array}$ & $\begin{array}{l}\text { Identification of giftedness } \\
\text { in severely and profoundaly } \\
\text { hearing impaired students }\end{array}$ \\
\hline
\end{tabular}

Fonte: Council for Exceptional Children (CEC), National Association for Gifted Children (NAGC) e Educational Resources Information Center (ERIC).

O texto "Twice exceptional" editorial do Council for Exceptional Children (CEC) (s/d) expõe a dificuldade de identificação do talento em estudantes com deficiências. Assinala que os testes convencionais e observacionais são inadequados e podem mascarar potenciais. Crianças com deficiência de audição podem não responder às orientaões e podem ter falta de vocabulário que reflita a complexidade de seus pensamentos.

O artigo "Children with communication disorder" expõe a dificuldade de audição que inclui 
surdez e perda de audição severa e mais leve. Assinala que, quando uma criança tem perda auditiva nos anos de desenvolvimento, todas as áreas de desenvolvimento podem ser afetadas significativamente, como o sistema de comunicação, a habilidade de interação com os outros e a aquisição de habilidades acadêmicas. A identificação precoce da perda de audição é importante para o ajustamento emocional e acadêmico.

Cosmos (s/d) pontua que o sistema não é desenhado para orientar as necessidades da criança que é superdotada e tem deficiência. Acrescenta que estudantes que têm alta gama de capacidades podem ter, em testes, seus scores anulados por seus déficits. Cosmos cita Cindy Little que orienta estratégias para crianças superdotadas com deficiência em sala de aula, quais sejam:

a) tecnologias apropriadas que podem apoiar e compensar as deficiências,

b) apoio tutorial e mentores que podem ser encontrados na mesma comunidade do aluno,

c) apoio de aconselhamento (ajudá-los com suas diferenças e frustrações);

d) elogiar sua força porque geralmente dá-se mais atenção às limitações;

e) uso de grupos flexíveis, compactação de currículo.

O artigo "Twice exceptional (gifted with special needs)" (s/d), apresentado pelo National Association for Gifted Children (NAGC), aponta crianças com dupla excepcionalidade (termo utilizado pelo NAGC) que podem ser mal percebidas como preguiçosas, teimosas, descuidadas ou desmotivadas. Assinala que os pais reconhecem o potencial dos filhos, notando sua capacidade marcante, como também, se confundem com as inconsistências. O artigo não indica a perda auditiva especificamente.

Vialle e Paterson (1996) discutem os problemas persistentes de identificação de altas habilidades ou superdotação em grupos minoritários. A ênfase no idioma facilita a discriminação desses grupos, embora a situação seja exacerbada para os estudantes com deficiência física e de aprendizagem. As pessoas com perdas auditivas têm o problema educacional relatado em sua capacidade de comunicação. Os referidos autores concluem que deve ser dado senso de orgulho e identidade em um ambiente educacional que reconheça suas potencialidades e não direcione para os déficits. Discutem, ainda, a valorização do bilinguismo e biculturalismo para os estudantes com perdas severas como elemento essencial para educação dos potencialmente elevados, além da contínua formação aos professores para que seja possível sua sensibilização.

Yewchuk e Bibby (1988) expõem estudo com 178 estudantes de 5 a 20 anos com severa perda auditiva e com acesso ao teste de inteligência não-verbal; indicação de professores e nomeação de pais. Nenhuma correlação houve entre os três procedimentos de identificação. Indicadores muito similares foram encontrados em estudantes com altas habilidades ou superdotação e perda auditiva.

Em visita ao site da SciELO, foram realizadas buscas com as seguintes palavras-chave: "dupla excepcionalidade" e "duplicidade de necessidades educacionais especiais", no entanto, nenhum resultado foi encontrado. Inseridas as palavras-chave "dupla necessidade educacional especial" houve um resultado, porém, irrelevante para o presente estudo por não pontuar as duas áreas contempladas, objetos dos estudos. Também, "altas habilidades/superdotação e deficiência" e "superdotação e deficiência" resultaram em 2 achados cada uma, entretanto, igualmente irrelevantes para esta pesquisa. As palavras "talento e deficiência" também foram buscadas, porém, não foram encontrados resultados.

A busca ocorreu em três fontes: Council for Exceptional Children (CEC), National Association for Gifted Children (NAGC) e Educational Resources Information Center (ERIC), no ano de 2012, e na Biblioteca Eletrônica Científica Online (SciELO Brasil), no ano de 2013. Apesar da atualidade desta pesquisa, as publicações são estrangeiras e não há como afirmar sua atualidade, pois, 
quatro dos trabalhos foram publicados sem data. Desta forma, os resultados permitiram constatar a escassez de pesquisas e publicações concernente à temática, mais evidentemente para a realidade brasileira.

Rangni (2012) assinala a importância de discutir a possibilidade da duplicidade de NEE em estudantes do sistema educacional brasileiro, como também, aponta que se faz necessário efetivar a formação de educadores com o intuito de voltar o olhar desses profissionais às potencialidades de seus alunos. Um dos fatores para o desconhecimento da dupla condição dos estudantes com potencial elevado e deficiência no meio educacional seja, possivelmente, a escassez de estudos sobre a temática. Sendo assim, Ourofino e Fleith (2005, p. 166) assinalam que "a dupla condição nos últimos anos, nota-se um tímido aumento no número de estudos empíricos sobre o tema".

Negrine (2009) e Rangni (2012) consideraram em seus estudos que os indivíduos com perda auditiva têm características semelhantes e detectáveis aos estudantes sem deficiência que podem ser reconhecidas pelos professores na escola.

Observou-se, com a análise dos dispositivos legais pertinentes à Educação e Educação Especial, que os estudantes com deficiência, transtorno global do desenvolvimento e altas habilidades ou superdotação (BRASIL, 1996, 2008, 2011, 2013) têm seus direitos ao atendimento educacional especializado, entretanto, os índices de matrículas dos alunos com altas habilidades ou superdotação são, ainda, irrisórios o que demonstra que há barreiras que impedem que as políticas públicas se efetivem para os escolares que possam estar na dupla condição, mesmo porque, como seria garantida a dupla matrícula orientada na legislação? Brasil (2011) aponta a dupla matrícula ao público alvo da Educação Especial que forem matriculados na escola regular, no entanto, a reflexão se faz para os casos da dupla condição.

\section{6 | Considerações finais}

Este artigo buscou apresentar uma reflexão sobre a duplicidade de NEE envolvendo os educandos com altas habilidades ou superdotação e perda auditiva. Nele, tentou se expor, também, como esses educandos são vistos na Educação Especial sob o aporte legal e sua consequência no atendimento educacional especializado.

Nessa perspectiva, o atendimento especial é feito por categorias de NEE que privilegiam umas em detrimento de outras e gessados em três grupos: altas habilidades ou superdotação, deficiência e transtorno global de desenvolvimento, orientação mais recente da Política Nacional de Educação Especial na Perspectiva da Educação Inclusiva e a Lei de Diretrizes e Bases, atualizada em 2013.

No caso dos estudantes com altas habilidades ou superdotação, eles estão protegidos pela legislação desde 1971, ratificada nas demais leis pertinentes à Educação Especial e Inclusiva e, ainda assim, são ínfimas as matrículas de educandos atendidos em todo o país, cujo índice é de 13.000 para uma população escolar que ultrapassa os 50 milhões.

Em sentido contrário, sobe vertiginosamente os serviços educacionais aos alunos com deficiência e síndromes (transtornos globais do desenvolvimento), no entanto, pouco se conhece e se discute sobre a possibilidade desses milhares de alunos possuírem potencialidades elevadas, contrariando a Organização Mundial da Saúde que pontua que, em qualquer população, 3,5 a $5 \%$ de seus indivíduos possuem altas habilidades ou superdotação, apenas considerando as áreas lógico-matemática e verbal. Outros índices mais elásticos podem estar em 15 a $20 \%$ de todas as áreas da capacidade humana, apenas para aqueles com indicadores de altas habilidades ou superdotação.

Sob essa perspectiva, os resultados indicam a necessidade de ações das políticas públicas em cadeia em prol do reconhecimento dessa parcela de estudantes, tais como: 
a) a prioridade no reconhecimento dos educandos que apresentam deficiência, não negligenciando suas possíveis potencialidades elevadas;

b) preparação dos ambientes escolares no que tange à formação de educadores e à implementação de recursos materiais e pedagógicos para o trabalho com estudantes com duplicidade de NEE;

c) uma maior exposição, o que não ocorre nem mesmo na legislação brasileira, do reconhecimento e garantias de atendimento fora das categorias assinaladas nos documentos oficiais.

Desta forma, percebe-se que a escola brasileira navega em águas turvas por não cumprir seu papel, incluindo o atendimento educacional especial a alunos com altas habilidades ou superdotação e, menos ainda, por desconhecer a possibilidade de incluir em programas os indivíduos com duplicidade de NEE.

Provavelmente, uma das causas que impede o reconhecimento dos potenciais em pessoas com dificuldades físicas, sensoriais, intelectuais, síndromes e funcionais situa-se nos mitos e preconceitos sobre essas pessoas. São vistas como incapazes e, por conta disso, são forçadas a se normalizarem no sistema educacional padronizante vigente em nossas escolas, fator que dificulta seu máximo desenvolvimento. 


\section{Referências}

ALENCAR, E. M. L. S; FLEITH, D. S. Superdotados: determinantes, educação e ajustamento. 2.ed. ver. São Paulo: EPU, 2001.

BRASIL. Política nacional de educação especial. Ministério da Educação e do Desporto. Secretaria de Educação Especial. Brasília, DF, 1994a.

. Declaração de Salamanca, 1994b. Disponível em: <www.mec.gov.br/seesp>. Acesso em: 7 abr. 2010.

. Lei de Diretrizes e Bases da Educação Nacional. Lei n. 9.394, de 20 de dezembro de 1996. Brasília, DF, 1996. Disponível em: <www.planalto.gov.br/legislação>. Acesso em: 7 abr. 2010.

. Ministério da Educação. Secretaria de Educação Especial. Adaptações curriculares em ação: desenvolvendo competências para atendimento às necessidades educacionais de alunos com altas habilidades/ superdotação. Brasília, DF, 2002.

Política nacional de educação especial na perspectiva da educação inclusiva. Brasília, DF, 2008. Disponível em: <www.mec.gov.br/seesp>. Acesso em: 7 abr. 2010.

Presidência da República. Lei n 10.436. Dispõe sobre a Língua Brasileira de Sinais. Casa Civil, Brasília, DF, 2002b. Disponível em: <http://www.planalto.gov.br/ ccivil_03/leis/2002//10436.htm>. Acesso em: 14 mar. 2014.

. Decreto $n^{\circ}$ 5.626. Regulamenta a Lei 10.436 de 24 de abril de 2002. Brasília, DF, 2005. Disponível em http:// www.planalto.gov.br/ccivil_03/_ato2004-2006/2005/decreto/ d5626.htm Acesso em: 12 mar. 2014.

. Censo Escolar, 2006. Disponível em: <http:// http:// www.inep.gov. br/basica/censo/default.asp>. Acesso em: 20 jan. 2007.

Decreto $n^{\circ} 7611$. Atendimento educacional especializado, Brasília, DF, 2011. Disponível em: <http:// www.planalto.gov.br/ccivil_03/_Ato2011-2014/2011/ Decreto/D7611.htm>. Acesso em: 4 abr. 2011.

. Lei $n^{\circ} 12.796$, de 4 de abril de 2013. Altera a Lei no 9.394 , de 20 de dezembro de 1996, que estabelece as diretrizes e bases da educação nacional, para dispor sobre a formação dos profissionais da educação e dar outras providências. Brasília, DF, 2013. Disponível em: <http:// www.planalto.gov.br/ccivil_03/_ato2011-2014/2013/lei/ 112796.htm>. Acesso em: 11 abr. 2014.

COUNCIL FOR EXCEPTIONAL CHILDREN. Children with communication disorders. [20--]. Disponível em:

$<$ http://www.cec.sped.org/AM/Template.

cfm?Section=Communicative_Disorders\&Template=/ TaggedPage/TaggedPageDisplay.

cfm\&TPLID=37\&ContentID=5626>. Acesso em: 25 fev. 2011.

Twice exceptional. [200-]. Disponível em: <http:// www.cec.sped.org/AM/Template.cfm?Section=Twice Exceptional\&Template=/TaggedPage/TaggedPageDisplay . cfm\&TPLID=37\&ContentID=5634>. Acesso em: $25 \mathrm{fev}$. 2011.

COSMOS, C. Imagine teaching Robin Williams. Twice exceptional children in your school. [200-].
Disponível em: <http://www.cec.sped.org/AM/Template. cfm?Section=Home\&TEMPLATE=/CM/ContentDisplay. cfm\&CONTENTID=5823>. Acesso em: 25 fev. 2011.

DELOU, C. M. Altas habilidades: canal saúde, Fio Cruz, 2012. Disponível em: <http://www.canal.fiocruz.br/video/ index.php?v=altas-habilidades>. Acesso em 11 ago. 2012.

EDUCATION RESOURCES INFORMATION CENTER. [20-]. Disponível em: <http://www.eric.org.uk/>. Acesso em: 20 fev. 2007.

FREITAS, S. N.; PÉREZ, S. G. P. B. Altas habilidades/ superdotação: atendimento especializado. Marília: Abpee, 2010.

GAGNÉ, F. From gifts to talents: The DMGT as a developmental model. In: STERNBERG, R. J.; DAVIDSON, J. E. (Orgs.). Conceptions of giftedness. 2.ed. Cambridge University Press, p. 98-119, 2005.

Building gifts into talents. Talent development according to the DMGT. Veröffentlicht In: news\&science. Begabtenförderung und Begabungsforschung. özbf, n. 19, 2 Ago. 2008. p. 27-30.

Construindo o talento a partir da dotação: breve visão do DMGT 2.0. In: ENCONTRO INTERNACIONAL DE EDUCADORES DE CEDET/ASPAT, 7., 2010, Poços de Caldas. Anais... Poços de Caldas: [s.n.], 2010.

GUENTHER, Z. C. Desenvolver capacidades e talentos: um conceito de inclusão. Petrópolis: Vozes, 2000.

Caminhos para desenvolver potencial e talento. Lavras: UFLA, 2011.

NATIONAL FOR EXCEPTIONAL CHILDREN. Twice exceptional (gifted with special needs). [20--]. Disponível em: <http://www.nagc.org/index.aspx?id=973>. Acesso em 20 fev. 2011.

MONTGOMERY, D. Gifted \& Talent children with special educational needs: double exceptionality. [S.I.]: A NACE/ Fulton Publication, 2003.

NEGRINI, T. A escola de surdos e os alunos com altas habilidades/superdotação: uma problematização decorrente do processo de identificação das pessoas surdas. 2009. Dissertação (Mestrado em Educação) Universidade Federal de Santa Maria, Santa Maria, 2009.

OMOTE, S. Deficiência e não-deficiência: recortes do mesmo tecido. Revista Brasileira de Educação Especial, v. 1, n.2, p 65-74. 1994.

OMOTE, S. Perspectivas para conceituação de deficiências. Revista Brasileira de Educação Especial, v. 2, $n^{\circ} 4$, p. 127-135. 1996.

OUROFINO, V.T.A.T.; FLEITH, D. S. Um estudo comparativo sobre a dupla excepcionalidade: supertdotação/hiperatividade. Avaliação Psicológica, v. 4, n. 2, p. 165-182, 2005.

OUROFINO, V. T. A. T. Altas habilidades e hiperatividade: a dupla excepcionalidade.

In: FLEITH, D.S.; ALENCAR, E. M. L. S. (Org.).

Desenvolvimento de talentos e

altas habilidades: orientação para pais e professores. Porto Alegre: Artmed, 2007. 
RANGNI, R. A. Reconhecimento em alunos com perdas auditivas no ensino básico. Tese (Doutorado em Educação Especial) - Universidade Federal de São Carlos, São Carlos, 2012.

RANGNI, R. A; COSTA, M. P. R.; DONEDA, M. R. V. Indivíduos talentosos: o filme gênio indomável como fonte de análise. Psicologia da Educação, v. 35, p.197- 213. 2012.

SABATELLA, M. L. P. Talento e superdotação: problema ou solução? Curitiba: IBPEX, 2005.

SALES, et al. Deficiência auditiva e surdez: visão clínica e educacional. Seminário apresentado na Universidade Federal de São Carlos, São Carlos, 2010.

SCIELO BRASIL. Biblioteca eletrônica científica on line. [20--]. Disponível em: <http://www.scielo.br/?lng=pt>. Acesso em 25 nov. 2013.

SASSAKI, R.K. Nomenclatura na área de surdez. 2005. Disponível em: <http://segundosprofes.blogspot.com. br/2010/12/nomenclatura-na-area-da-surdez-romeu.html>. Acesso em: 18 mar. 2014.
SMITH, D. D. Superdotação e altas habilidades. In: Introdução à educação especial: ensinar em tempos de exclusão. 5.ed. Porto Alegre: Artmed, 2008.

WINSTANLEY, C. Gifted children with hearing impairment. In: Montgomery, D. Gifted \& Talent children with special educational needs: double exceptionality. [S.I.]: A NACE/ Fulton Publication, 2003.

VIALLE, W.; PATERSON, J. Constructing sensitive education for gifted deaf students. [20--]. Disponível em: <http://www.eric.ed.gov/ERICWebPortal/search/ simpleSearch.jsp?newSearch=true\&eric

tField=\&searchtype=basic\&pageSize=10\&ERICExtSearch_ SearchValue_0=giftedness+and+deafness\&eric_ displayStartCount $=1 \&$ pageLabel=ERICSearchResult\&ERICExtSearch_ SearchType_0=kw>. Acesso em: 25 fev. 2011.

YEWCHUCK, C; BIBBY, M. A. Identification of giftedness in severely and profoundly hearing impaired students. 1988. Disponível em: <http://www.eric.ed.gov/>. Acesso em: 25 fev. 2011. 